\title{
Methanol, Ethanol and Acetone Sensing Using AACVD-grown Tungsten Oxide Nanoneedles
}

\author{
Thamri A ${ }^{1}$, Baccar $\mathbf{H}^{1}$, Annanouch $\mathrm{FE}^{2}$, Llobet $\mathrm{E}^{2}$ and Abdelghani $\mathrm{A}^{\text {** }}$
}

${ }^{1}$ Carthage University, Nanotechnology Group, National Institute of Applied Science and Technology, Bp676, Centre Urbain Nord, 1080 Charguia Cedex, Tunisia ${ }^{2}$ MINOS-EMaS, Universitat Rovirai Virgili, Avda. Països Catalans 26, 43007 Tarragona, Spain

\begin{abstract}
We report on the aerosol assisted chemical vapor deposition growth of either pure or gold-nanoparticle decorated tungsten oxide nanoneedles, directly integrated onto alumina transducers for achieving resistive gas sensors. The morphology of the different samples grown is studied by scanning electron microscopy and by atomic force microscopy. The performance of these nanomaterials for the detection of methanol, ethanol and acetone vapors at ppm levels is studied. It is found that the detection of these species is possible even in a background of nitrogen where oxygen is present at ppm levels only. The presence of Au nanoparticles on the surface of tungsten oxide nanoneedles significantly increases sensitivity towards the vapors considered. Additionally, Au loading enhances the kinetics of surface reactions and helps decreasing response time. The detection mechanism and the role of Au nanoparticles is discussed in light of the experimental findings.
\end{abstract}

Keywords: Gold nanoparticles; Tungsten oxide nanoneedles; Aerosol assisted chemical vapor deposition resistive gas sensors

\section{Introduction}

Volatile organic compounds (VOCs) including aromatics such as benzene or toluene, nitrogen oxides (NOx), hydrogen sulfide or ammonia are among the most dangerous pollutants released each year by anthropogenic sources. They have harmful effects both on human beings and animals [1-3]. The widespread detection and continuous monitoring of these organic pollutants require inexpensive, fast, sensitive, selective and stable sensor devices. In the last years, metal oxide nanowire materials (e.g., $\mathrm{SnO}_{2}, \mathrm{WO}_{3}$ ) have been studied for developing gas sensors with superior performance in sensitivity, power consumption and long-term stability [4-6]. Tungsten oxide nanoneedles represent a very promising material for gas detection [7]. The decoration of metal oxide nanoneedles with different metal nanoparticles helps increasing and tuning the sensitivity of the resulting nanomaterials towards gases or vapors. Various methods have been used to manufacture pure and metal nanoparticle decorated metal oxide nanoneedles, such as sol-gel [8,9], spray pyrolysis [10], spin-coating [11,12], electrodeposition [13,14], and the aerosol assisted chemical vapor deposition (AACVD) technique [15-19].

In this paper, we have developed two types of sensors based on tungsten oxide nanomaterials. While the first type employs pure tungsten oxide nanoneedles, the second is based on gold-nanoparticle decorated tungsten oxide nanoneedles. The growth of the pure or Audecorated nanoneedles was performed, in a single step, by AACVD method directly onto platinum interdigitated electrodes, which had been printed previously onto alumina substrates. The morphology of the nanostructures grown was investigated by scanning electron microscopy (SEM) and by atomic force microscopy (AFM). An impedance spectroscopy measurement technique was employed to characterize the different sensors in the presence of vapors of methanol, ethanol and acetone in a balance of nitrogen. The loading of tungsten oxide nanoneedles with gold nanoparticles significantly changes response intensity and sensitivity towards the vapors tested and a discussion on the sensing mechanism is given in light of the experimental findings.

\section{Materials and Methods}

\section{Sensor substrate and AACVD deposition}

The AACVD process is quite simple, it consists of delivering the appropriate precursors in the form of an aerosol into the reaction zone in which the substrate is held $[20,21]$.

In this paper, either pure or gold-nanoparticle decorated tungsten oxide nanonneedles were grown by AACVD onto alumina substrates in view of obtaining resistive gas sensors. Substrates consisted of alumina tiles $\left(0.8 \times 0.8 \mathrm{~cm}^{2}\right)$ in which interdigitated platinum electrodes (electrode gap was 500 microns) and a resistive platinum heater had been screen-printed onto the front and back sides of the tile, respectively [21].

The precursor solutions were prepared as follows. For growing pure tungsten oxide nanoneedles, $50 \mathrm{mg}$ of tungsten hexacarbonyl $\left(\mathrm{W}(\mathrm{CO})_{6}\right)$ (Sigma-Aldrich) were dissolved in a mixture of $15 \mathrm{ml}$ of acetone (Sigma-Aldrich) and $5 \mathrm{ml}$ of methanol (Sigma-Aldrich). For the growth of Au-decorated tungsten oxide nanoneedles $50 \mathrm{mg}$ of $\mathrm{W}(\mathrm{CO})_{6}$ (Sigma-Aldrich) were dissolved in $15 \mathrm{ml}$ of acetone (SigmaAldrich), $7 \mathrm{mg}$ of tetrachloroauric acid trihydrate $\left(\mathrm{HAuCl}_{4} \bullet 3 \mathrm{H}_{2} \mathrm{O}\right)$ were dissolved in $6 \mathrm{ml}$ of methanol and subsequently added to the tungsten oxide precursor solution. Prior to run the AACVD process, alumina substrates with screen-printed Pt electrodes and heater were cleaned with ethanol and then with acetone. The temperature of the reactor was set to $500^{\circ} \mathrm{C}$ and to $380^{\circ} \mathrm{C}$ for growing pure tungsten oxide nanoneedles and Au-decorated tungsten oxide nanoneedles, respectively. An

*Corresponding author: Adnane Abdelghani, Carthage University, Nanotechnology Group, National Institute of Applied Science and Technology Bp676, Centre Urbain Nord, 1080 Charguia Cedex, Tunisia, Tel: +216 71703 629; E-mail: aabdelghan@yahoo.fr

Received May 26, 2016; Accepted June 13, 2016; Published June 20, 2016

Citation: Thamri A, Baccar H, Annanouch FE, Llobet E, Abdelghani A (2016) Methanol, Ethanol and Acetone Sensing Using AACVD-grown Tungsten Oxide Nanoneedles. J Nanomed Nanotechnol 7: 380. doi:10.4172/21577439.1000380

Copyright: @ 2016 Thamri A, et al. This is an open-access article distributed under the terms of the Creative Commons Attribution License, which permits unrestricted use, distribution, and reproduction in any medium, provided the original author and source are credited. 
Citation: Thamri A, Baccar H, Annanouch FE, Llobet E, Abdelghani A (2016) Methanol, Ethanol and Acetone Sensing Using AACVD-grown Tungsten Oxide Nanoneedles. J Nanomed Nanotechnol 7: 380. doi:10.4172/2157-7439.1000380

ultrasonic humidifier bath was used to create an aerosol from the precursor solutions kept in a glass flask. The aerosols were transported to the substrate, which was placed in the reactor stainless steel chamber, by using a carrier gas $\left(\mathrm{N}_{2}\right)$ with a flow rate of $0.5 \mathrm{~L} / \mathrm{min}$. The deposition time ranged between 40 to 50 minutes, until all the precursor passed through the reactor chamber [22,23]. After deposition, an annealing step of the films was carried in an oven at $500^{\circ} \mathrm{C}$ for $3 \mathrm{~h}$ under a constant $200 \mathrm{ml} / \mathrm{min}$ flow of dry air [24]. After that, the substrates mounted to a PCB support using platinum wires and a silver soldering paste. Figure la shows two of the sensors produced ready for being tested.

\section{Morphology of the gas-sensitive films}

The morphology of the deposited films was examined using Environmental Scanning Electron Microscopy (ESEM-FEI Quanta $600,20 \mathrm{keV})[16,17,23]$. Atomic Force Microscopy (AFM) images were obtained using an MFP-3D Origin AFM set-up (Oxford Instrument, USA) in air. The images were obtained using tapping mode with standard cantilever holder equipped by an AC240TS silicon tip with a resonance frequency of $\approx 70 \mathrm{KHz}$. The scan was carried using a scanning rate of $0.5 \mathrm{~Hz}$.

\section{Gas sensing measurements}

Electrical measurements for studying the gas sensing properties of the two nanomaterials towards different concentrations of methanol, ethanol and acetone vapors were performed using an HP 4192A impedance analyzer. Since all devices showed a resistive behavior at frequencies below $100 \mathrm{kHz}$, for all the measurements performed a fixed operating frequency of $1 \mathrm{kHz}$ was selected $[25,26]$. This allowed us to monitor sensor response (i.e., resistance change) in real time. A bottle of dry nitrogen connected to two mass flow meters and a thermostated bubbler were used to generate reproducible concentrations of the different volatile compounds tested. This system was connected to a stainless-steel sensor chamber $\left(35 \mathrm{~cm}^{3}\right.$ in volume), which could host two sensors. More details on this set-up can be found in references [26,27].

The variation of the resistance of the two sensors in the presence of different concentrations of the volatile species in a balance of nitrogen was studied. The sensor response is defined as the normalized resistance:

$$
\frac{\Delta \mathrm{R}}{\mathrm{R}_{0}}(\%)=\frac{\mathrm{R}-\mathrm{R}_{0}}{\mathrm{R}_{0}} \times 100
$$

Where $\mathrm{R}$ the resistance is measured under a given vapor, and $\mathrm{R}_{0}$ is the sensor baseline resistance under nitrogen.

\section{Results and Discussion}

\section{Morphological characterization of the sensing films}

Electron scanning microscopy: The cristalline order of pure and Au-decorated tungsten oxide nanoneedles grown by AACVD was studied in previous works $[23,24,28]$. Figure 1 shows the film morphology observed by SEM for pure and Au-decorated tungsten oxide nanoneedles grown by AACVD. A film consists of high density wire-like structures. SEM images show the presence of randomly oriented nanoneedles, which is in good agreement with our previously reported results $[16,23,24]$.

In a previous work [28], the sample analysis using energy dispersive $\mathrm{X}$-ray analysis (EDX) shows the presence of tungsten and oxygen with an atomic percentage of 16.73 and 57.52 respectively. However, EDX analysis confirms the presence of gold with a percentage of 0.88 at $\%$. These results confirm the successful co-deposition of metal nanoparticles and tungsten oxide nanoneedles in a single step employing AA-CVD.
Atomic force microscopy: Figures 2 and 3 shows the film morphology observed with atomic force microscopy of pure and $\mathrm{Au}$ decorated tungsten oxide nanoneedles. It shows vertical nanoneedles deposited homogenously in micrometer scale $(2.5 \times 2.5 \mu \mathrm{m})$ and some of them inclined.These nanoneedles have perfect sharp tips with a small roughness value. A roughness of $121 \mathrm{~nm}$ and $108 \mathrm{~nm}$ for $\mathrm{WO}_{3}$ and gold nanoparticle decorated $\mathrm{WO}_{3}$ nanoneedles was obtained, respectively.

According to SEM results, the diameters of nanoneedles range between 80 and $120 \mathrm{~nm}$. According to a horizontal section (AFM analysis), the diameter of nanoneedles is about $100 \mathrm{~nm}$.

\section{Gas sensing analysis}

To find the optimal operation temperature for the two types of nanomaterials, sensor response versus operating temperature at a fixed concentration of methanol, ethanol and acetone was studied (Figure 4). Figure 5 shows the responses of both tungsten oxide nanoneedles

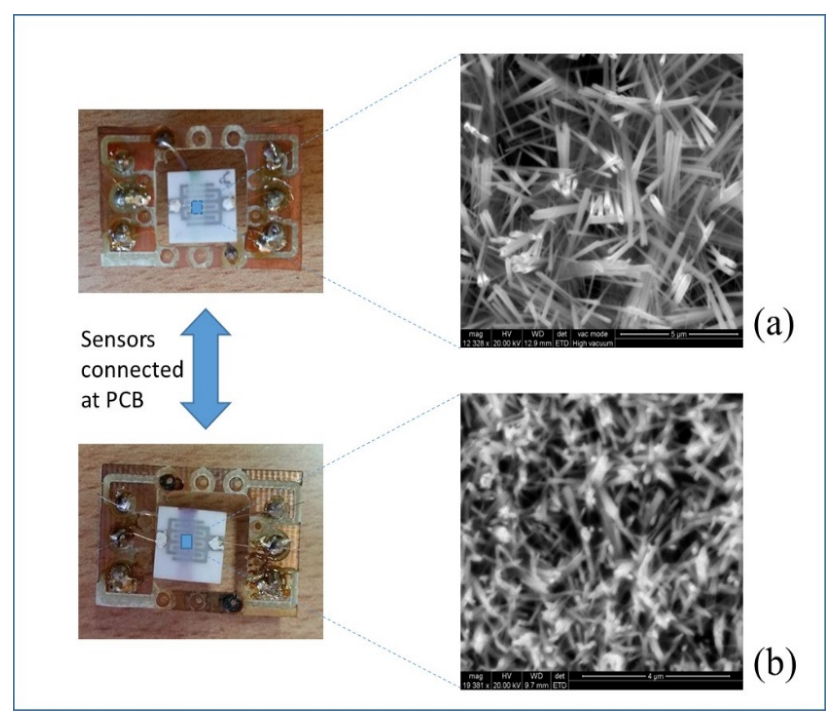

Figure 1: Sensors ready for testing after deposition of nanoneedles by AACVD and wire-bonding to a PCB (right) and ESEM micrographs of pure tungsten oxide (a) and Au-decorated tungsten oxide (b) nanoneedles.

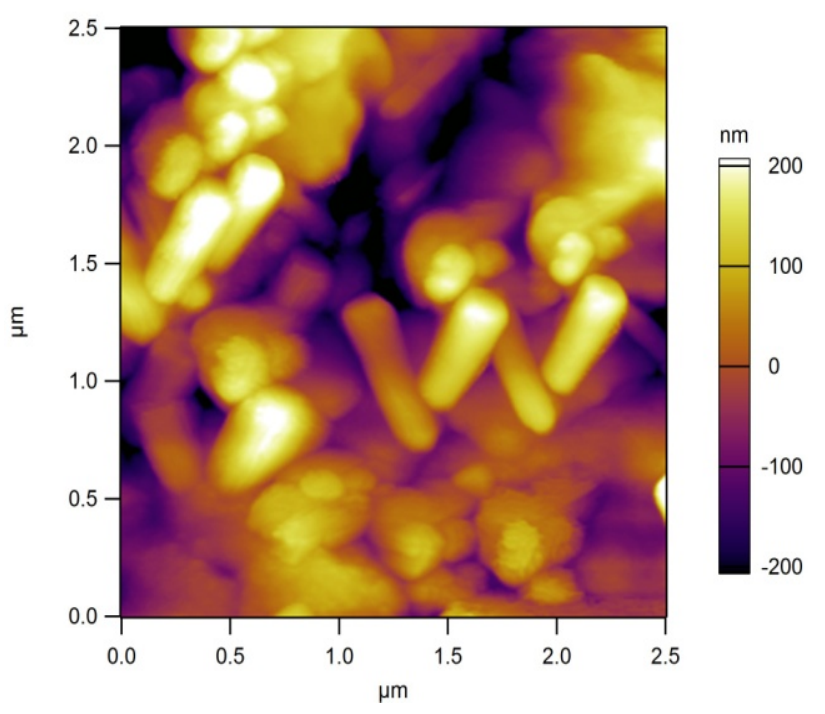

Figure 2: Topography AFM image of tungsten oxide nanoneedles. 


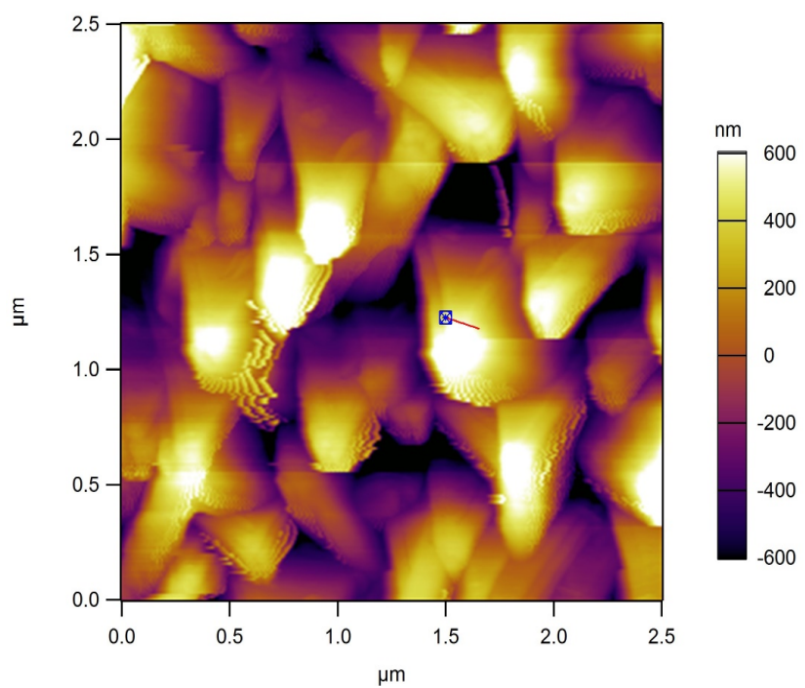

Figure 3: Topography AFM image of gold-nanoparticle decorated tungsten oxide nanoneedles.

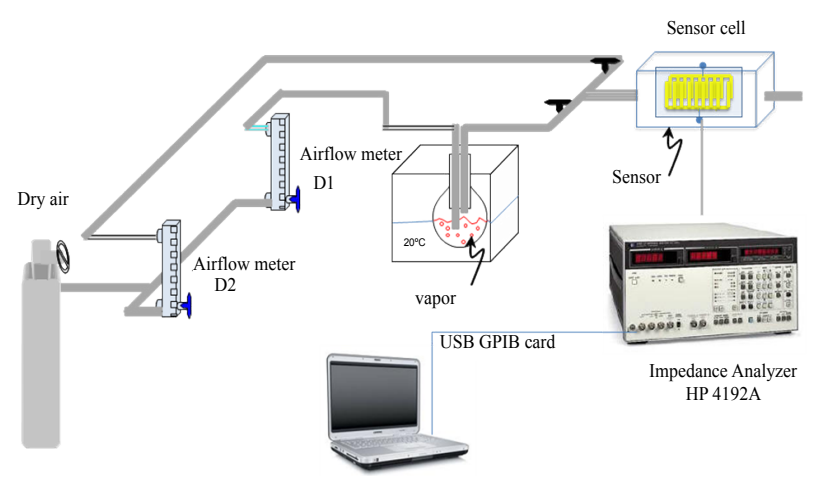

Figure 4: Experiment set up for gas sensing.

and gold nanoparticle decorated tungsten oxide nanoneedles towards a fixed ethanol concentration of $5 \mathrm{ppm}$ when the sensors were operated at different temperatures. A higher response for the two types of sensors is reached when the operation temperature is $250^{\circ} \mathrm{C}$. The optimal operating temperature of the sensor is related mainly to the formation of appropriate oxygen surface species, but also to the adsorption and further reaction of reducing species with oxygen adsorbates.

The two types of sensors were exposed to different concentrations of ethanol, methanol and acetone vapors at $250^{\circ} \mathrm{C}$. Figures 6 and 7 shows the sensor responses to different concentrations of vapors for pure and $\mathrm{Au}$-decorated tungsten oxide nanoneedles, repectively. The decrease in resistance observed can be explained by the nature of the vapors injected, which are oxidizing vapors and by tungsten oxide behaving as an n-type semiconductor material [2]. Although the response signals are clear, regaining the baseline when the sensor surface is cleaned is somewhat difficult. Indeed, in some cases, a noisy baseline resistance is achieved (Figures 6 and 7). This can be explained by the fact that the balance gas employed is nitrogen and not air. Under these conditions and given the experimental set-up employed, only traces of oxygen (tens of ppm) may be present in the test chamber, especially during the cleaning phase.

Figure 8 shows calibration curves for the two types of sensors and the different vapors measured. The sensitivity of the tungsten oxide nanoneedle sensors (i.e., the slope of the curves) is higher for methanol than to the others vapors (Table 1). The improvement in sensitivity that results from the Au loading of tungsten oxide nanoneedles is similar for the alcohols (about 37\% increase) and higher for acetone (about 67\% increase). The detection mechanism for reducing species involves the adsorption of these volatile compounds on the surface of the semiconductor and further reaction with oxygen adsorbates, which eventually results in electrons that are initially trapped at oxygen adsorbates being released to the conduction band of the semiconductor. This mechanism, which is largely accepted to explain the detection of reducing species in a balance of dry air, has been shown to hold also when oxygen is present at concentration levels that range between few tens to few hundreds of ppm [29,30]. The use of metal nanoparticles and, in particular Au on the surface of tungsten oxide films has been shown to be advantageous for enhancing sensitivity towards some target species. Metal nanoparticles that decorate the surface of semiconductor metal oxides can improve their gas sensing properties by increasing the number of appropriate oxygen surface species or by catalytically decomposing the target species generating more reactive species that in turn spill over the surface of the metal oxide. Although there is not enough data to univocally determine which of the two aforementioned mechanisms is dominant here, the fact that the improvement in sensitivity is similar for the alcohols and acetone suggests that the role of $\mathrm{Au}$ nanoparticles may be to increase the number of appropriate oxygen adsorbates, thus increasing the number of active reactive sites for the detection of the different reducing vapors measured. Additionally, the loading with Au nanoparticles has also an effect in response dynamics (by increasing the kinetics of surface reactions). The response time of $\mathrm{Au}$-tungsten oxide nanoneedle sensors to the different vapors tested is significantly lower than that of pure tungsten oxide nanoneedle sensors (Table 2).

\begin{tabular}{|c|c|c|c|}
\hline & Ethanol & Methanol & Acetone \\
\hline $\begin{array}{c}\text { Tungsten oxide } \\
\text { nanoneedles }\end{array}$ & $0.8 \% . \mathrm{ppm}^{-1}$ & $1.94 \% . \mathrm{ppm}^{-1}$ & $0.68 \% . \mathrm{ppm}^{-1}$ \\
\hline $\begin{array}{c}\text { Au nanoparticle } \\
\text { decorated tungsten } \\
\text { oxide nanoneedles }\end{array}$ & $1.1 \% . \mathrm{ppm}^{-1}$ & $2.65 \% . \mathrm{ppm}^{-1}$ & $1.14 \% . \mathrm{ppm}^{-1}$ \\
\hline
\end{tabular}

Table 1: Sensor sensitivity (slope of calibration curves) to the different vapors tested.

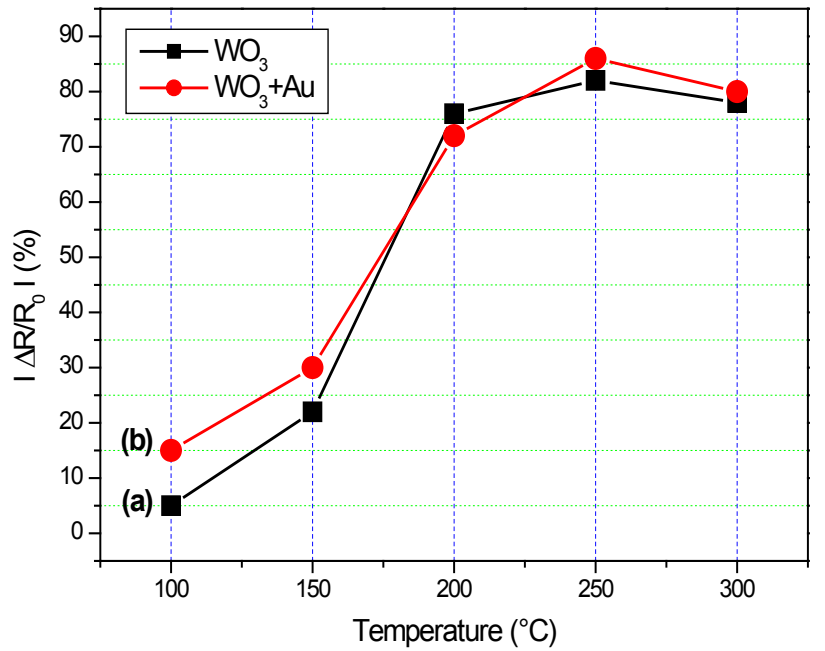

Figure 5: Esponse of tungsten oxide nanoneedles (a) and Au-nanoparticle decorated tungsten oxide nanoneedles (b) towards ethanol $5 \mathrm{ppm}$ at different operation temperatures. 


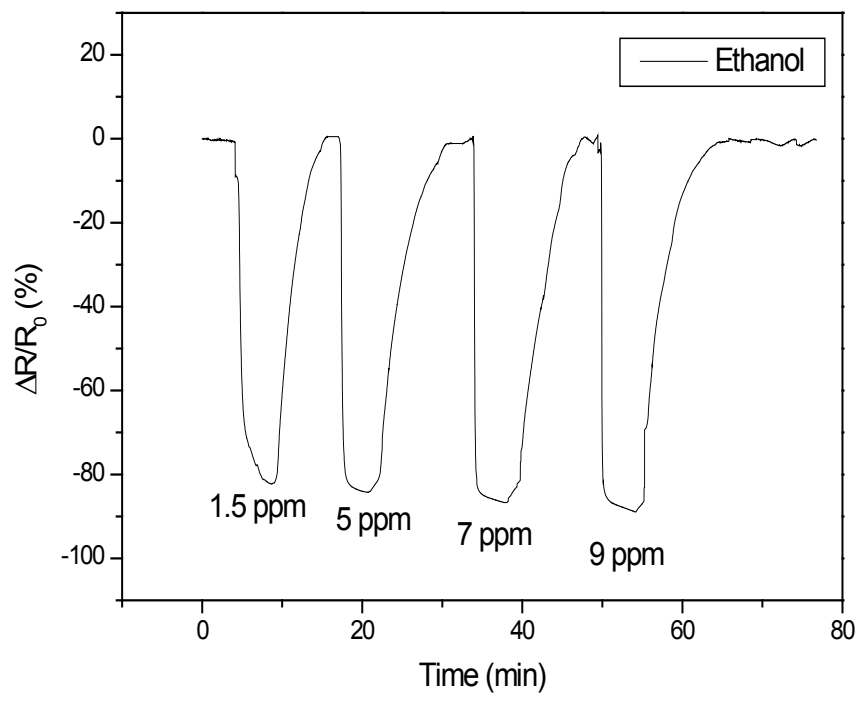

(a)

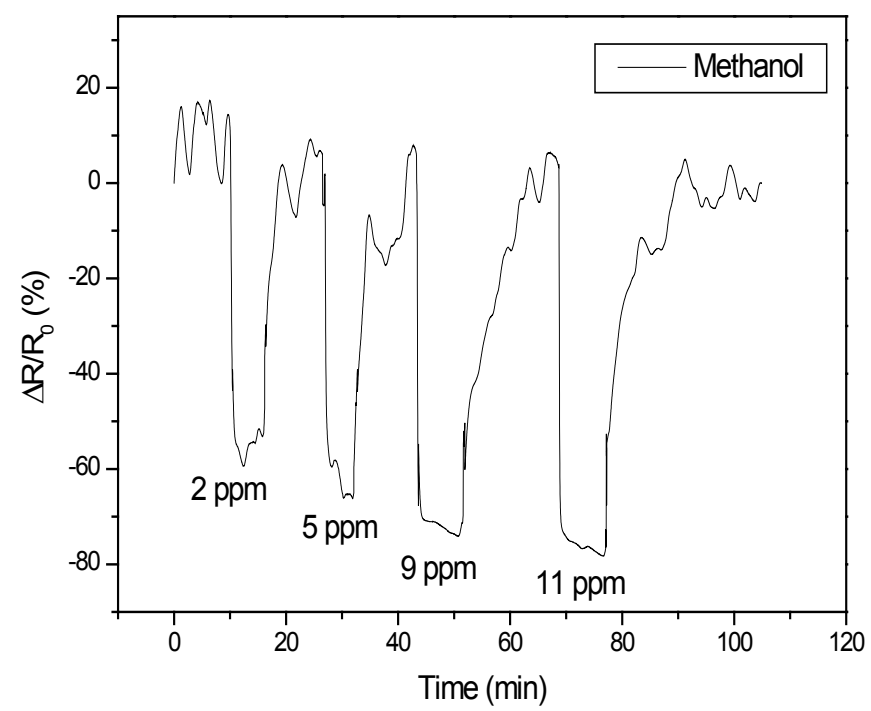

(b)

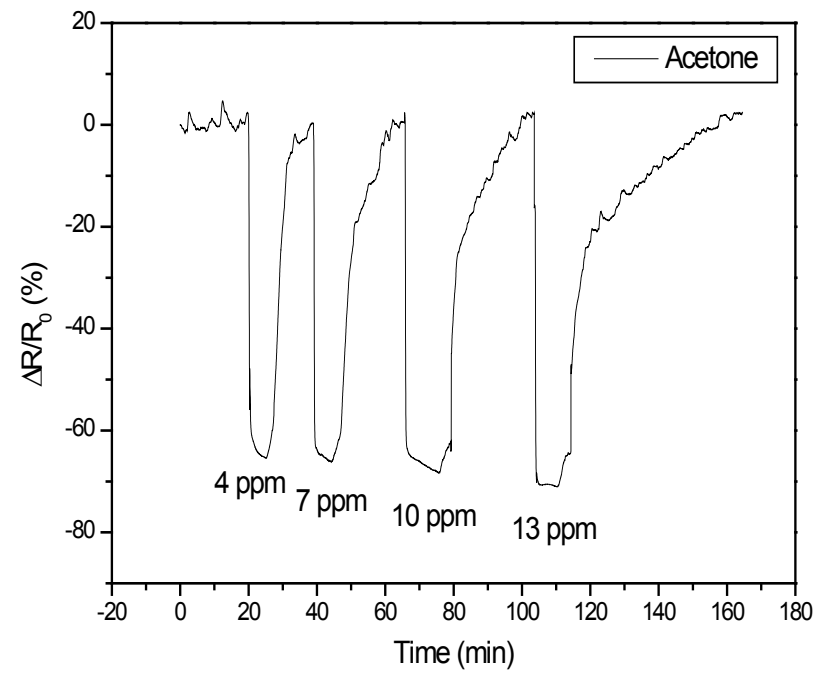

(c)

Figure 6: Sensor responses of tungsten oxide nanoneedles to various concentrations of (a) ethanol, (b) methanol and (c) acetone, at an operating temperature of $250^{\circ} \mathrm{C}$

\begin{tabular}{|c|c|c|c|}
\hline & Ethanol & Methanol & Acetone \\
\hline $\begin{array}{c}\text { Tungsten oxide } \\
\text { nanoneedles }\end{array}$ & 60 & 48 & 72 \\
\hline $\begin{array}{c}\text { Au nanoparticle } \\
\text { decoratedtungsten } \\
\text { oxide nanoneedles }\end{array}$ & 48 & 30 & 60 \\
\hline
\end{tabular}

Table 2: Sensor response times (s) to the different vapors tested.

\section{Conclusión}

In this paper, the AACVD technique was implemented as a simple and effective method for the deposition of tungsten oxide nanoneedles onto interdigitated electrodes printed on alumina substrates. Two different types of sensors based on pure tungsten oxide nanoneedles and on $\mathrm{Au}$ nanoparticle-decorated tungsten oxide nanoneedles were fabricated and tested. The sensors were operated at the optimal temperature of $250^{\circ} \mathrm{C}$ for detecting vapors of methanol, ethanol and acetone at units of ppm levels in a balance of nitrogen. The response intensity and the sensitivity of $\mathrm{Au}$-decorated $\mathrm{WO}_{3}$ nanoneedle sensors were found to be higher than those of pure $\mathrm{WO}_{3}$ nanoneedles for the different volatiles tested. This has been initially attributed to Au nanoparticles increasing the number of appropriate oxygen species adsorbed on the surface of tungsten oxide nanoneedles, which increases the number of available reaction sites for the different reducing volatile species tested. In a future work, and in view to enhance selectivity and discrimination ability of tungsten oxide nanoneedles, specific molecules could be covalently immobilized to gold nanoparticles (e.g. after thiol functionalisation), which would help tuning their response to gases/vapors.

\section{Acknowledgements}

This work is funded by the Science for Peace and Security Program of the North Atlantic Treaty Organization under grant no. SFP984511. PC gratefully acknowledges a PhD Scholarship from URV and EL acknowledges the support 


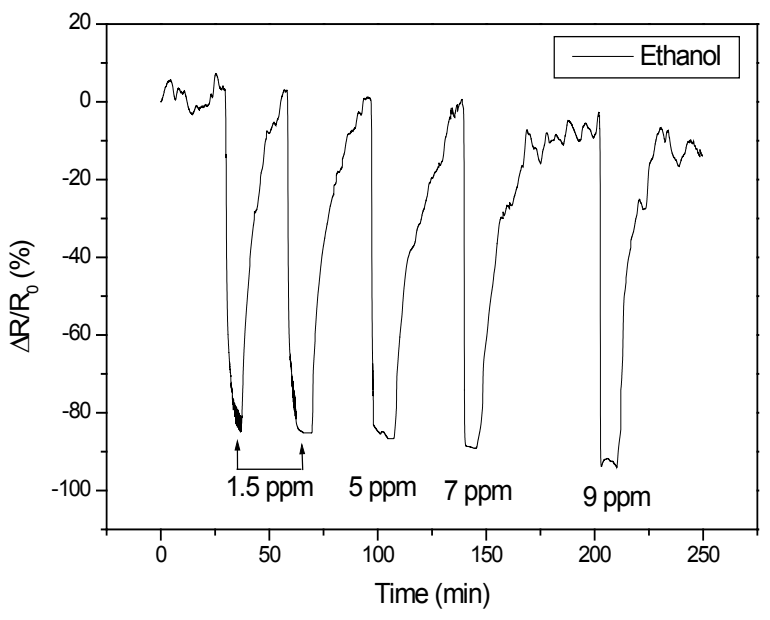

(a)

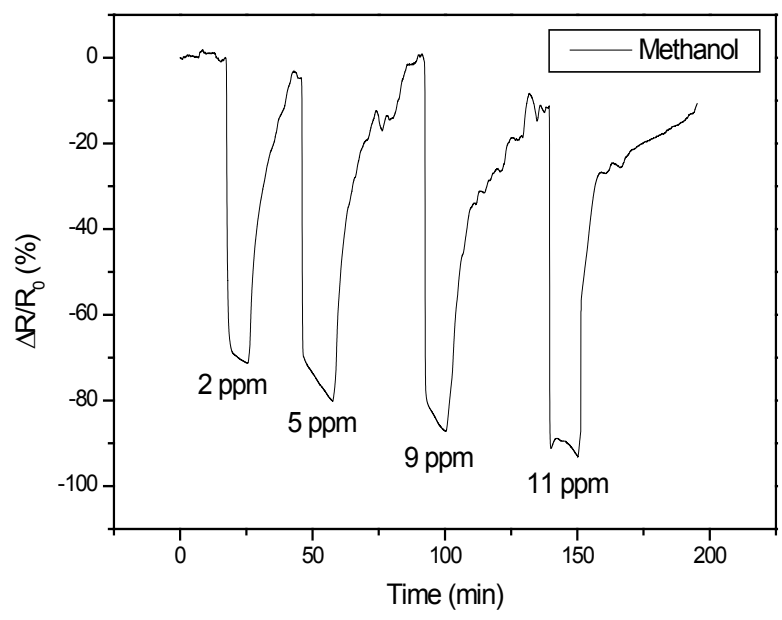

(b)

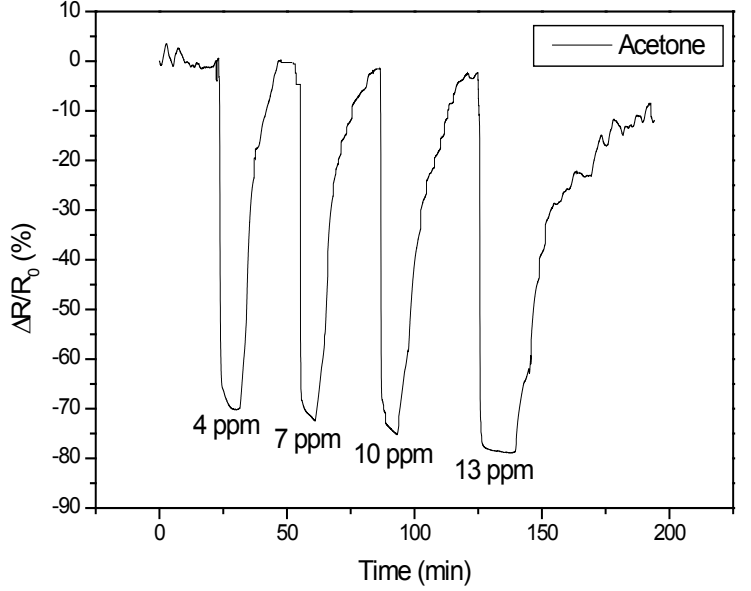

(c)

Figure 7: Sensor responses of Au-nanoparticle decorated tungsten oxide nanoneedles to various concentrations of (a) ethanol, (b) methanol and (c) acetone, at an operating temperature of $250^{\circ} \mathrm{C}$.

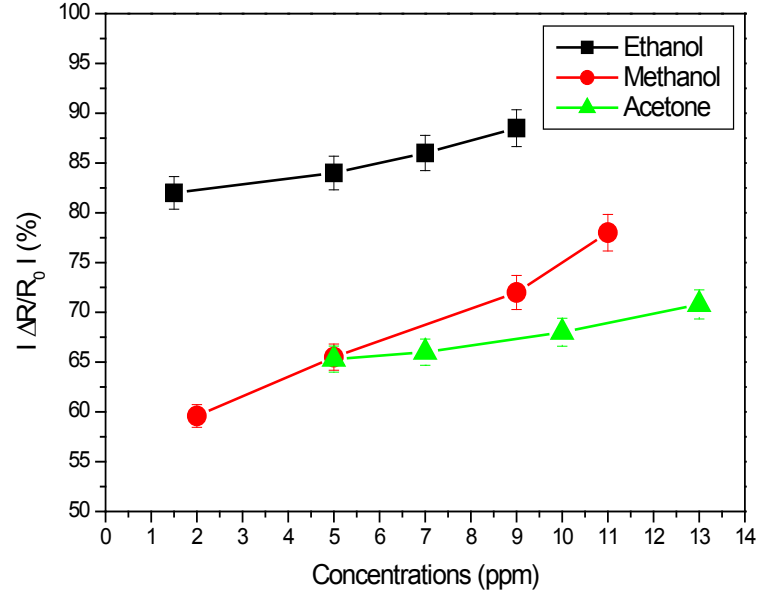

(a)

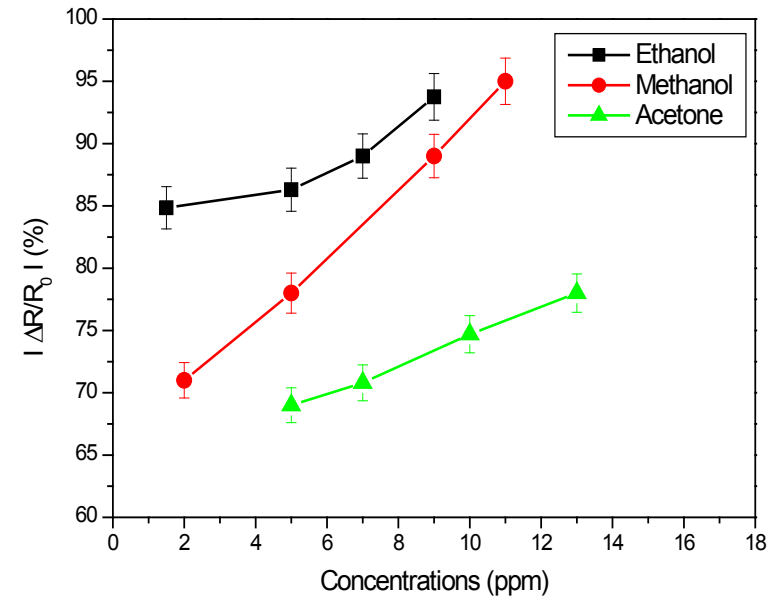

(b)

Figure 8: Calibration curves for (a) tungsten oxide nanoneedles (b) Au-nanoparticle decorated tungsten oxide nanoneedles to the different volatile compounds tested. 
Citation: Thamri A, Baccar H, Annanouch FE, Llobet E, Abdelghani A (2016) Methanol, Ethanol and Acetone Sensing Using AACVD-grown Tungsten Oxide Nanoneedles. J Nanomed Nanotechnol 7: 380. doi:10.4172/2157-7439.1000380

of the Catalan Institution for Research and Advanced Studies under the ICREA Academia Award. Pr. A. Abdelghani dedicates this work to the memory of Ezzidine Machat (father of Sondes Machat ) died the $17^{\text {th }}$ of January 2016.

\section{References}

1. (2010) WHO Guidelines for Indoor Air Quality: Selected Pollutants. Geneva: World Health Organization.

2. Kampa M, Castanas E (2008) Human health effects of air pollution. Environ Pollut 151: 362-367.

3. Andreja S, Dimitrije M, Svetlana Stanišic S, Zoran M, Andrej Š (2015) Forecasting of VOC emissions from traffic and industry using classification and regression multivariate methods. Science of the Total Environment 521-522: $19-26$.

4. Minh Vuong N, Minh Hieu N, NhatHieu H, Yi H, Kim D, et al. (2014) Ni2O3decorated $\mathrm{SnO} 2$ particulate films for methane gas sensors. Sensors and Actuators B 192: 327-333.

5. Ma S, Hu M, Zeng P, Li M, Yan W, Qin Y (2014) Synthesis and low-temperature gas sensing properties of tungsten oxide nanowires/porous silicon composite. Sensors and Actuators B 192: 341-349.

6. Leidingera M, Sauerwalda T, Conradb T, Reimringerb W, Venturac G, et al (2014) Selective Detection of Hazardous Indoor VOCs Using Metal Oxide Gas Sensors. Procedia Engineering 87: 1449 - 1452.

7. Vallejos S, Stoycheva T, Umek P, Navio C, Snyders R, et al. (2011) Au nanoparticle-functionalised WO3 nanoneedles and their application in high sensitivity gas sensor devices. Chem Commun (Camb) 47: 565-567.

8. Liu C, Liu Z, Li J, Li Y, Han J, et al. (2013) Cu doping ZnO/ZnSnanorods serve as the photoanode to enhance photocurrent and conversion efficiency. Microelectron Eng 103: 12-16.

9. Reda SM (2010) Synthesis of $\mathrm{ZnO}$ and $\mathrm{Fe} 2 \mathrm{O} 3$ nanoparticles by sol-gel method and their application in dye-sensitized solar cells. Mater Sci Semicond Process 13: 417-425.

10. Bettini LG, Dozzi MV, Foglia FD, Chiarello GL, Selli E, et al. (2015) Mixedphase nanocrystalline $\mathrm{TiO} 2$ photocatalysts produced by flame spray pyrolysis. Applied Catalysis B: Environmental 178: 226-232.

11. Chang H, Chen CH, Kao MJ, Chien SH, Chou CY (2013) Photoelectrode thin film of dye-sensitized solar cell fabricated by anodizing method and spin coating and electrochemical impedance properties of DSSC. Appl Surf Sci 275: 252-257.

12. Habibi M, Sardashti MK (2008) Structure and morphology of nanostructured zinc oxide thin films prepared by dip-coating vs. spin-coating methods. J Iran ChemSoc 5: 603-609.

13. Enache CS, Liang YQ, Van de Krol R (2011) Characterization of structured a-Fe2O3 photoanodes prepared via electrodeposition and thermal oxidation of iron. Thin Solid Films 520: 1034-1040.

14. Tseng CJ, Wang CH, Cheng KW (2012) Photoelectrochemical performance of gallium doped AgInS2 photoelectrodes prepared by electrodeposition process. Sol Energy Mater Sol Cells 96: 33-42.
15. Bhachu DS, Sankar G, Parkin IP (2012) Aerosol assisted chemical vapor deposition of transparent conductive zinc oxide films. Chem Mater 24: 4704-4710.

16. Annanouch FE, Vallejos S, Stoycheva T, Blackman C, Llobet E (2013) Aeroso assisted chemical vapour deposition of gas sensitive nanomaterials. Thin Solid Films 548: 703-709.

17. Walters G, Parkin IP (2009) Aerosol assisted chemical vapour deposition of $\mathrm{ZnO}$ films on glass with noble metal and p-type dopants; use of dopants to influence preferred orientation. Appl Surf Sci 255: 6555-6560.

18. Ehsan MA, Tahir AA, Hamid M, Mazhar M, Wijayantha K, et al. (2011) Deposition of iron titanate/titania ceramic composite thin films from a single molecular precursor. Inorg Chim Acta 376: 189-194.

19. Tahir AA Wijayantha KGU, Mazhar M, McKee V (2010) ZnFe2O4 thin films from a single source precursor by aerosol assisted chemical vapour deposition. Thin Solid Films 518: 3664-3668.

20. Ariffin SN, Lim HN, Talib ZA, Pandikumar A, Huang NM (2015) Aerosol-assisted chemical vapor deposition of metal oxide thin films for photoelectrochemical water splitting. International journal of hydrogen energy 40: 2115-2131.

21. Stoychevaa T, Vallejosa S, Blackmanb C, Monizb SJA, Caldererc J, et al (2012) Important considerations for effective gas sensors based on metal oxidenanoneedles films. Sensors and Actuators B 161: 406- 413

22. Ivanov P, Hubalek J, Malysz K, Prasek J, Vilanova X, et al. (2004) Aroute toward more selective and less humidity sensitive screen-printed SnO2and WO3 gas sensitive layers. Sens Actuator B-Chem 100: 221-227.

23. Annanouch F, Vallejos S, Blackman C, Correig X, Llobet E, et al. (2012) CO and $\mathrm{H} 2$ sensing with $\mathrm{CVD}$-grown tungsten oxide nanoneedles decorated with $\mathrm{Au}, \mathrm{Pt}$ or Cu nanoparticles. Procedia Engineering 47: 904 - 907.

24. Annanouch FE, Camara M, Ramírez JL, Briand D, Llobet E (2014) Gas Sensing Properties of Metal-decorated Tungsten Oxide Nanowires Directly Grown onto Flexible Polymeric Hotplates. Procedia Engineering 87: 700 - 703.

25. Hafaiedh I, El Euch W, Clement P, Llobet E, Abdelghani A (2013) Multi-walled carbon nanotubes for volatile organic compound detection. Sensors and Actuators B 182: 344-350.

26. Baccar H, Thamri A, Clément P, Llobet E, Abdelghani A (2015) Pt- and Pddecorated MWCNTs for vapour and gas detection at room temperature. Beilstein J Nanotechnol 6: 919-927.

27. Thamri A, Baccar H, Hafaid I, Clément $P$, Llobet $E$, et al. (2015) Rhodium-decorated MWCNTs for detecting organic vapors. Int J Nanotechnol 12: 562-571.

28. Annanouch FE, Stoycheva T, Vallejos S, Blackman C, Correig X, et al.(2013) AA-CVD growth and ethanol sensing properties of pure and metal decorated WO3 nanoneedles. International Journal of Nanotechnology 10: 455-469.

29. Bârsan N, Hübner M, Weimar U (2011) Conduction mechanisms in SnO2 based polycrystalline thick film gas sensors exposed to $\mathrm{CO}$ and $\mathrm{H} 2$ in different oxygen backgrounds. Sensors and Actuators B: Chemical 157: 510-517.

30. Schmid W, Bârsan N, Weimar U (2004) Sensing of hydrocarbons and CO in low oxygen conditions with tin dioxide sensors: possible conversion paths. Sensors and Actuators B: Chemical 103: 362-368. 